\title{
Phase I dose escalation safety study of nanoparticulate paclitaxel (CTI 520I0) in normal dogs
}

This article was published in the following Dove Press journal:

International Journal of Nanomedicine

I| October 20 | |

Number of times this article has been viewed

\author{
Sandra M Axiak' \\ Kim A Selting' \\ Charles J Decedue ${ }^{2}$ \\ Carolyn J Henry ${ }^{1,3}$ \\ Deborah Tate' \\ Jahna Howell ${ }^{2}$ \\ K James Bilof ${ }^{\prime}$ \\ Dae Y Kim ${ }^{4}$
}

'Department of Veterinary Medicine and Surgery, University of Missouri, Columbia, MO, USA; ${ }^{2}$ CritiTech Inc, Lawrence, KS, USA; ${ }^{3}$ Department of Internal Medicine, Division of Hematology and Oncology; ${ }^{4}$ Department of Veterinary Pathobiology, University of Missouri, Columbia, MO, USA
Correspondence: Kim Selting University of Missouri Veterinary Medicine and Surgery, 900 East Campus Drive, Columbia, MO, 6521I, USA

$\mathrm{Tel}+\mid \mathrm{I} 5738827821$

Fax + I 5738840705

Email seltingk@missouri.edu
Background: Paclitaxel is highly effective in the treatment of many cancers in humans, but cannot be routinely used in dogs as currently formulated due to the exquisite sensitivity of this species to surfactant-solubilizing agents. CTI 52010 is a formulation of nanoparticulate paclitaxel consisting of drug and normal saline. Our objectives were to determine the maximally tolerated dose, dose-limiting toxicities, and pharmacokinetics of CTI 52010 administered intravenously to normal dogs.

Methods: Three normal adult hound dogs were evaluated by physical examination, complete blood count, chemistry profile, and urinalysis. Dogs were treated with staggered escalating dosages of CTI 52010 with a 28-day washout. All dogs were treated with a starting dosage of $40 \mathrm{mg} / \mathrm{m}^{2}$, and subsequent dosages were escalated at $50 \%(\operatorname{dog} 1), 100 \%(\operatorname{dog} 2)$, or $200 \%$ ( $\operatorname{dog} 3$ ) with each cycle, to a maximum of $240 \mathrm{mg} / \mathrm{m}^{2}$. Dogs were monitored by daily physical assessment and weekly laboratory evaluation. Standard criteria were used to grade adverse events. Plasma was collected at regular intervals to determine pharmacokinetics. Dogs were euthanized humanely, and necropsy was performed one week after the last treatment.

Results: The dose-limiting toxicity was grade 4 neutropenia and the maximum tolerated dosage was $120 \mathrm{mg} / \mathrm{m}^{2}$. Grade 1-2 gastrointestinal toxicity was noted at higher dosages. Upon post mortem evaluation, no evidence of organ (liver, kidney, spleen) toxicity was noted.

Conclusion: CTI 52010 was well tolerated when administered intravenously to normal dogs. A starting dosage for a Phase I/II trial in tumor-bearing dogs is $80 \mathrm{mg} / \mathrm{m}^{2}$.

Keywords: paclitaxel, nanoparticle, canine

\section{Introduction}

Paclitaxel is an antimitotic taxane isolated from the western yew (Taxus brevifolia). ${ }^{1}$ The mechanism of action of paclitaxel is to promote microtubules to form polymers which stabilize the resulting complex and inhibit microtubule disassembly. This results in inhibition of cell proliferation and induction of apoptosis. ${ }^{1,2}$ Paclitaxel has become an important component of cancer treatment, with significant antitumor activity against many types of malignancies, including ovarian, breast, head and neck, esophageal, and bladder carcinomas. ${ }^{3}$ Use of paclitaxel in dogs is limited due to an acute hypersensitivity reaction caused by the cosolvents required to make paclitaxel soluble. Standard forms of paclitaxel contain ethanol and polyethoxylated castor oil to solubilize it, and dogs are exquisitely sensitive to this formulation. ${ }^{3,4}$ Protein-bound paclitaxel, another common form, is a fine particle formulation coated with human serum albumin to increase its water solubility. ${ }^{5}$ However, using a foreign protein, such as human albumin in dogs, can also result in a hypersensitivity reaction. ${ }^{6}$ 
Standard practice in human medicine for the administration of paclitaxel includes the premedication of patients with drugs to block both the histamine 1 and histamine 2 receptors, in an attempt to counteract the effects of sensitivity to ethanol and polyethoxylated castor oil. ${ }^{3}$ This has led to the creation of several formulations of paclitaxel in recent years to eliminate the need for ethanol and polyethoxylated castor oil and therefore the need for premedications. ${ }^{7-10}$ CTI 52010 is the simplest of these new formulations, consisting only of paclitaxel in a nanoparticulate form with saline. Production of CTI 52010 relies on supercritical carbon dioxide processing. The nanoparticle size, 600-700 nm, allows the drug to exist as a stable suspension in saline without cosolvent, suspensionenhancing agents, or other excipients. ${ }^{7,9}$

For many cancers in dogs, the current repertoire of surgery, radiation, and chemotherapy has remained relatively unchanged. Common cancers such as metastatic lung cancer, lymphoma, prostate carcinoma, and osteosarcoma have not benefited from any major advance in the past 20 years. New treatment options are necessary if we are to improve the quality of life for companion animals diagnosed with cancer. Paclitaxel therapy has been attempted in dogs with spontaneously occurring tumors, and preliminary efficacy was noted with breast and bone cancer. ${ }^{4}$ However, toxicity was high; $64 \%$ of dogs had hypersensitivity reactions despite heavy pretreatment with diphenhydramine and corticosteroids, and $12 \%$ had treatment-related deaths. ${ }^{4}$ Yet, preliminary efficacy suggests that this group of drugs would expand our treatment options for dogs if a tolerable formulation existed. ${ }^{4}$ CTI 52010 has been well tolerated in preclinical rodent models and does not contain substances to which dogs should react. ${ }^{7}$ Therefore, CTI 52010 represents a novel chemotherapeutic agent that should be investigated as an anticancer agent in dogs.

Spontaneously occurring cancers in dogs are increasingly recognized as a model for human cancer. Tumors in dogs share many clinical and molecular similarities to the corresponding cancer in people and provide the opportunity for an integrated comparative drug development pathway. Although rodent models are important for analyzing biologic pathways in cancer formation and preliminary drug efficacy, pet dogs develop cancer naturally with an intact immune system and an environment shared with their human counterparts. Incorporating dogs with spontaneously forming cancer into drug development will bridge the gap between rodent models and humans. Using dogs as a translational model can be used to confirm drug targets and provides proof of concept, in addition to providing information on best treatment schedules, pharmacokinetics, and drug toxicities prior to Phase I trials in people. ${ }^{11-13}$

The objectives of this study were to determine the maximally tolerated dose, dose-limiting toxicities, and plasma pharmacokinetics of intravenously delivered CTI 52010 in normal dogs to inform the starting dosage for a Phase II trial in tumor-bearing dogs.

\section{Materials and methods Drug production}

CTI 52010 was produced by previously published methods. ${ }^{9}$ Briefly, paclitaxel was recrystallized using the supercritical carbon dioxide process known as precipitation with compressed antisolvent. Paclitaxel was dissolved in an organic solvent (acetone), which was sprayed as fine droplets into a chamber containing supercritical carbon dioxide. The result was removal of solvent from the solute into the supercritical carbon dioxide, causing the solute (drug) to precipitate as nanoparticles with reduced crystal size. These mild processing conditions cause the drug to remain largely free of surface charge, with less tendency to agglomerate than fine particles prepared by grinding or ballistic methods. Furthermore, the result of this production method is a formulation of nanoparticulate paclitaxel consisting only of paclitaxel (without coating or matrix) and physiologic saline. This process was conducted in compliance with current good manufacturing practices.

\section{Study design}

Three normal adult hound dogs were obtained, housed, and handled according to the University of Missouri Animal Care and Use Committee approved protocol. Baseline evaluation consisted of physical examination, complete blood count, serum chemistry profile, and complete urinalysis. Serum chemistry profile evaluated renal values (blood urea nitrogen, creatinine), proteins (albumin, globulins), liver enzymes (alkaline phosphatase, alanine aminotransferase, gamma-glutamyl transpeptidase), total bilirubin, glucose, and electrolytes. Dogs were treated with staggered escalating doses of CTI 52010 with a 28-day washout period. Following sedation and placement of a peripheral catheter for drug administration, a jugular catheter was placed for blood collection. All dogs were treated with an initial starting dosage of $40 \mathrm{mg} / \mathrm{m}^{2}$ on day 0. CTI 52010 suspension $5 \mathrm{mg} / \mathrm{mL}$ was delivered without dilution into a freely running line of saline over 30 minutes. Subsequent dose escalations for each treatment were scheduled as 50\% (dog 1), 100\% $(\operatorname{dog} 2)$, and $200 \%(\operatorname{dog} 3)$ each cycle to a maximum dosage 
of $240 \mathrm{mg} / \mathrm{m}^{2}$, meaning the final dose escalation in $\operatorname{dog} 3$ was $100 \%$ over the previous dose (Table 1). Dogs were scheduled for three total treatments, or until a dose-limiting toxicity was observed. Once a dose-limiting toxicity was documented, the next lowest dosage was considered the maximum tolerated dose for the purpose of identifying a starting dosage for dogs with spontaneously occurring tumors. This study design was developed to minimize the number of dogs and number of treatments required to reach our endpoints.

\section{Monitoring schedule}

All dogs were monitored on a daily basis by physical assessment and weekly with chemistry profiles, and urinalysis. A complete blood count was performed biweekly following the first treatment cycle to determine nadirs of neutrophils and platelets and was assessed weekly thereafter. A coagulation panel assessing prothrombin time and activated partial thromboplastin time was performed prior to each treatment and one week after each treatment. Additionally, a log book was kept for each dog, noting appetite, attitude, activity level, emesis, and any other health-related events. Hypersensitivity was evaluated by direct observation of each dog following treatment for clinical signs of an allergic reaction (facial swelling, flushing, urticaria, dyspnea, fever). Adverse events were graded according to Veterinary Co-operative Oncology Group adverse events criteria, version $1 .{ }^{14} \mathrm{~A}$ dose-limiting toxicity was defined as that which resulted in grade 4 hematologic toxicity, grade 3 or higher toxicity of any other organ, or febrile grade 3 hematologic toxicity (Table 2). Dogs were humanely euthanized one week after the last treatment and underwent a complete post mortem evaluation.

\section{Blood sampling}

Whole blood $(3 \mathrm{~mL})$ was collected for pharmacokinetic analysis at nine specified time points, ie, at minutes $0,15,30$, and 45 , and then at hours 1, 2, 4, 8, and 24 following the start of drug infusion. Blood was collected into ethylenediamine tetraacetic acid tubes, and samples were centrifuged within 20 minutes of sample collection. Plasma was collected immediately and frozen at $-20^{\circ} \mathrm{C}$ until assayed. Samples for each treatment group were assayed concurrently within three months of collection.

\section{Pharmacokinetic data analysis}

Actual doses were calculated based on body surface area of the animals on treatment day. Samples were collected at time points listed above. A simplified high performance liquid chromatography (HPLC) separation was used for analysis; samples were spiked with docetaxel as an internal standard and extracted, then analyzed by HPLC. HPLC separation for paclitaxel was optimized using 5 micron L43 packing in a $6 \mathrm{~mm} \times 250 \mathrm{~mm}$ column. Starting conditions were a flow rate of $1.5 \mathrm{~mL} /$ minute, column temperature of $30^{\circ} \mathrm{C}$, and a mobile phase consisting of acetonitrile and water in a ratio of 9:11. The elution was isocratic and the run time was 15 minutes. Initial runs contained only paclitaxel and docetaxel standards, and operating parameters were adjusted to achieve full separation of paclitaxel from the internal standard docetaxel. After reproducible conditions were established and equipment calibrated for good laboratory practice compliance, spiked samples of canine plasma were analyzed to determine recovery efficiency and a calibration curve was constructed. One milliliter samples of blank canine plasma were spiked with five levels of paclitaxel ranging from $2 \mathrm{ng}$ to $100 \mathrm{ng}$ and with the internal standard, docetaxel. Samples were extracted with ethyl acetate, separated by centrifugation, dried by evaporation, and reconstituted in acetonitrile/water for injection into the HPLC. Limit of detection, limit of quantification, percent recovery, slope, intercept, and correlation coefficient were determined and a standard operating procedure was written for the protocol. The standard curves were used to calculate plasma concentration levels of treated animals (Figure 1).

Blood samples for pharmacokinetic analysis were drawn at the aforementioned time points. Plasma was collected and frozen for delivery to CritiTech for analysis. The samples were spiked with docetaxel as internal standard and extracted as described above, then analyzed by the HPLC method on a Hitachi L7000 series HPLC with L7200 autosampler, L7400 ultraviolet detector, and operated with TotalChrom software.

Paclitaxel concentrations were determined by comparison with the standard curve and the blank sample run with each batch analyzed. Multiple dilutions of samples were as needed to ensure that paclitaxel levels fell within the range of the standard curve. Maximum plasma concentration, plasma

Table I Dosing schedule of CTI 52010

\begin{tabular}{|c|c|c|c|c|c|c|}
\hline \multirow[t]{2}{*}{ Day } & \multicolumn{2}{|l|}{ Dog I } & \multicolumn{2}{|l|}{ Dog 2} & \multicolumn{2}{|l|}{ Dog 3} \\
\hline & $\%$ increase & Dosage $\left(\mathrm{mg} / \mathrm{m}^{2}\right)$ & $\%$ increase & Dosage $\left(\mathrm{mg} / \mathrm{m}^{2}\right)$ & $\%$ increase & Dosage $\left(\mathrm{mg} / \mathrm{m}^{2}\right)$ \\
\hline 0 & 0 & 40 & 0 & 40 & 0 & 40 \\
\hline 28 & 50 & 60 & 100 & 80 & 200 & 120 \\
\hline 56 & 50 & 90 & 100 & 160 & 100 & 240 \\
\hline
\end{tabular}


Table 2 Veterinary Co-operative Oncology Group criteria for adverse events following chemotherapy (version I)

\begin{tabular}{|c|c|c|c|c|c|}
\hline Adverse event & $\begin{array}{l}\text { Grade I } \\
\text { (mild) }\end{array}$ & $\begin{array}{l}\text { Grade } 2 \\
\text { (moderate) }\end{array}$ & $\begin{array}{l}\text { Grade } 3 \\
\text { (severe) }\end{array}$ & $\begin{array}{l}\text { Grade } 4 \\
\text { (life-threatening) }\end{array}$ & $\begin{array}{l}\text { Grade } 5 \\
\text { (death) }\end{array}$ \\
\hline Nausea & $\begin{array}{l}\text { Loss of appetite } \\
\text { with no alteration } \\
\text { in eating habits }\end{array}$ & $\begin{array}{l}\text { Salivation, lick smacking } \\
<12 \text { hours }\end{array}$ & $\begin{array}{l}\text { Salivation, lick smacking } \\
>12-24 \text { hours }\end{array}$ & $\begin{array}{l}\text { Salivation, lick } \\
\text { smacking }>24 \text { hours }\end{array}$ & $\mathrm{N} / \mathrm{A}$ \\
\hline Vomiting & $\begin{array}{l}<3 \text { episodes in } \\
24 \text { hours }\end{array}$ & $\begin{array}{l}3-5 \text { episodes in } 24 \text { hours; }<3 \\
\text { episodes per day for } 2-5 \text { days; } \\
\text { parenteral fluids indicated for } \\
<24 \text { hours }\end{array}$ & $\begin{array}{l}>5 \text { episodes in } 24 \text { hours } \\
\text { or vomiting for }>4 \text { days } \\
\text { Parenteral fluids indicated } \\
\text { for }>24 \text { hours }\end{array}$ & $\begin{array}{l}\text { Life-threatening } \\
\text { (hemodynamic } \\
\text { collapse) }\end{array}$ & Death \\
\hline Diarrhea & $\begin{array}{l}\text { Increase of }>2 \\
\text { stools per day } \\
\text { over baseline }\end{array}$ & $\begin{array}{l}\text { Increase of } 2-6 \text { stools per } \\
\text { day over baseline; parenteral } \\
\text { fluids indicated }<24 \text { hours }\end{array}$ & $\begin{array}{l}\text { Increase of }>6 \text { stools } \\
\text { per day over baseline, } \\
\text { incontinence, parenteral } \\
\text { fluids }>24 \text { hours }\end{array}$ & $\begin{array}{l}\text { Life-threatening } \\
\text { (hemodynamic } \\
\text { collapse) }\end{array}$ & Death \\
\hline Neutropenia & $\begin{array}{l}\text { I500/ } \mu \mathrm{L} \text {, lower } \\
\text { limit of normal }\end{array}$ & $1000-1499 / \mu \mathrm{L}$ & $500-999 / \mu \mathrm{L}$ & $<500 \mu \mathrm{L}$ & $\mathrm{N} / \mathrm{A}$ \\
\hline Thrombocytopenia & $\begin{array}{l}100,000 / \mu \mathrm{L} \text {, lower } \\
\text { limit of normal }\end{array}$ & $50,000-99,000 / \mu \mathrm{L}$ & $25,000-49,000 / \mu \mathrm{L}$ & $<25,000 / \mu \mathrm{L}$ & $\mathrm{N} / \mathrm{A}$ \\
\hline
\end{tabular}

Note: Copyright@ 2004. John Wiley and Sons. Reproduced with permission from Veterinary Cooperative Oncology Group. Veterinary Co-operative oncology group - common criteria for adverse events (VCOG-CTCAE) following chemotherapy or biological antineoplastic therapy in dogs and cats v1.0. Vet Comp Oncol. 2004;2:194-2I3.14

half-life $\left(\mathrm{t} 1 / 2_{0-24}\right)$, volume of distribution, mean residence time, and area under the curve were calculated for each test animal using PK Solutions software (PK Solutions Pharmacokinetics Data Analysis version 2.0 from Summit Research Services Montrose, CO).

\section{Post mortem examination}

One week following the last treatment, all dogs were humanely euthanized with administration of intravenous pentobarbital and gross postmortem examination with histopathology of all organs performed. Additionally, tissue samples were collected during post mortem examination for extraction of CTI 52010.

\section{Tissue homogenization and extraction}

Liver, spleen, and kidney tissue samples $(0.5 \mathrm{~g})$ were collected from each dog during post mortem examination

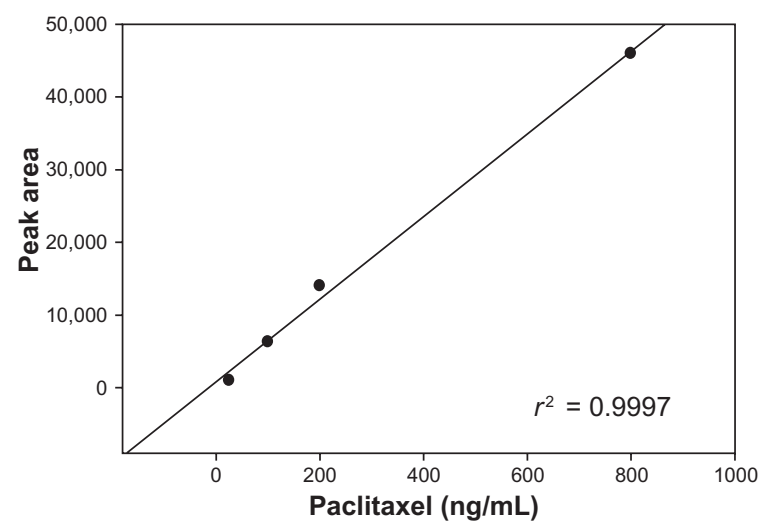

Figure I Paclitaxel standard curve used to calculate plasma concentration levels of treated animals. and were placed into separate $15 \mathrm{~mL}$ polypropylene conical tubes with $1 \mathrm{~mL}$ HPLC water. The samples were then placed in a $-35^{\circ} \mathrm{C}$ acetone/water/dry ice bath. Using a Misonix sonifier with a 3/16 inch tip, at power level five, the tissues were homogenized by placing the tip on tissue, and blending for 35 seconds, resulting in liquid homogenate that was transferred to polyethylene microcentrifuge tubes in $400 \mu \mathrm{L}$ aliquots. Twenty microliters of internal standard was added to each sample, samples were vortexed, and $1 \mathrm{~mL}$ of methyl-t-butyl ether was added. The samples were then shaken by hand for 10 minutes, followed by 10 minutes of centrifugation. Samples were placed in an acetone/dry ice bath at $-50^{\circ} \mathrm{C}$ for two minutes, and the methyl-t-butyl ether layer was decanted into polyethylene microcentrifuge tubes. A CentriVap was used for 15 minutes to dry samples, and samples were then reconstituted and transferred to autosample vials with microinserts. Aliquots of $100 \mu \mathrm{L}$ were used for HPLC.

\section{Results}

Three adult hound dogs were obtained from a certified dealer and determined healthy based on physical examination. Complete blood counts, coagulation panels, serum chemistry profiles, and urinalyses were within normal limits in all three dogs at baseline (data not shown).

Side effects are summarized in Table 3. No evidence of hypersensitivity was noted in any dog at any dosage. No gastrointestinal toxicity was noted in any dog at dosages up to $120 \mathrm{mg} / \mathrm{m}^{2}$, other than Grade 1 nausea in one dog treated with $90 \mathrm{mg} / \mathrm{m}^{2}$. Grade 1 and 2 gastrointestinal toxicity and grade 
Table 3 Summary of side effects seen with increasing doses of CTI 52010 using the Veterinary Co-operative Oncology Group (VCOG) - common criteria for adverse events version I criteria following chemotherapy (see also Table 2). Each cell represents a single adverse event in one dog

\begin{tabular}{|c|c|c|c|c|}
\hline Side effect & $\begin{array}{l}\text { Vomiting } \\
\text { (Grade) }\end{array}$ & $\begin{array}{l}\text { Nausea } \\
\text { (Grade) }\end{array}$ & $\begin{array}{l}\text { Neutropenia } \\
\text { (Grade) }\end{array}$ & $\begin{array}{l}\text { Thrombocytopenia } \\
\text { (Grade) }\end{array}$ \\
\hline \multicolumn{5}{|c|}{ Dose $\left(\mathrm{mg} / \mathrm{m}^{2}\right)$} \\
\hline 40 & & & & Grade I \\
\hline \multicolumn{5}{|l|}{60} \\
\hline 80 & & & Grade 2 & Grade I \\
\hline 90 & & Grade I & Grade I & Grade I \\
\hline 120 & & & Grade I & \\
\hline 160 & Grade 2 & & Grade 4 (DLT) & Grade 3 \\
\hline 240 & Grade I & & Grade 4 (DLT) & Grade I \\
\hline
\end{tabular}

Note: Copyright@ 2004. John Wiley and Sons. Reproduced with permission from Veterinary Cooperative Oncology Group. Veterinary Co-operative oncology group - common criteria for adverse events (VCOG-CTCAE) following chemotherapy or biological antineoplastic therapy in dogs and cats v1.0. Vet Comp Oncol. 2004:2:194-213. ${ }^{14}$

Abbreviation: DLT, dose-limiting toxicity.

4 myelotoxicity were noted at $160 \mathrm{mg} / \mathrm{m}^{2}$ and $240 \mathrm{mg} / \mathrm{m}^{2}$. When treated with $80-120 \mathrm{mg} / \mathrm{m}^{2}$, grades 1 and 2 myelotoxicity occurred. A mild to moderate thrombocytopenia occurred in most dogs 10-14 days following treatment. One dog experienced an elevation in both prothrombin time and partial thromboplastin time one week following treatment with $40 \mathrm{mg} / \mathrm{m}^{2}$ and $120 \mathrm{mg} / \mathrm{m}^{2}$ doses. The coagulation abnormalities resolved within three weeks, prior to the next scheduled treatment. The dose-limiting toxicity was neutropenia at a nadir of seven days, and the maximum tolerated dose was determined to be $120 \mathrm{mg} / \mathrm{m}^{2}$.

Dogs were humanely euthanized using pentobarbital administered intravenously. Upon post mortem examination of all dogs, no evidence of toxicity was noted in the liver, kidney, or spleen (Figures 2 and 3). Drug accumulation was noted in the liver and spleen, but not the kidney (Figure 4). Drug concentrations in the liver and spleen were proportional to dose. Liver tissue concentrations of CTI 52010

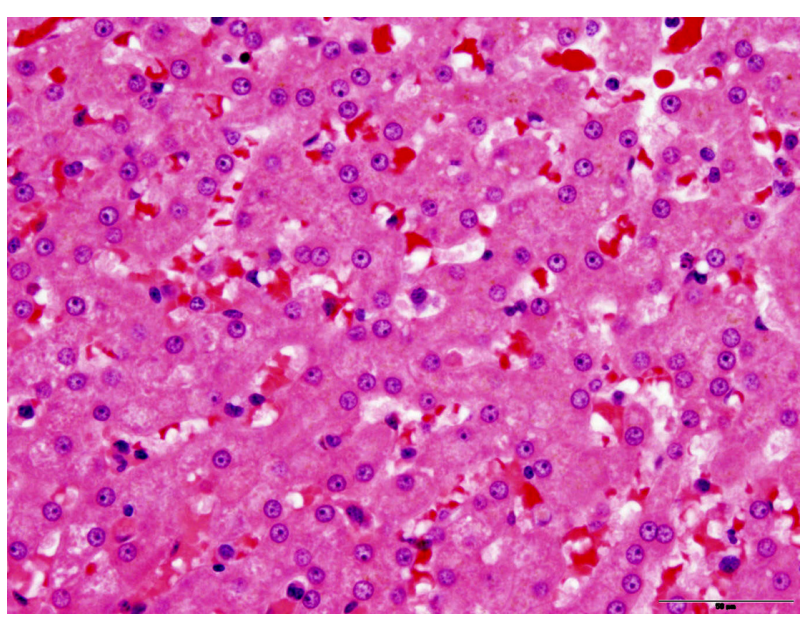

Figure 2 Histopathology of the liver in a treated dog, showing no evidence of change compared with normal liver. were $94.49 \mu \mathrm{g} / \mathrm{g}, 54.89 \mu \mathrm{g} / \mathrm{g}$, and $17.58 \mu \mathrm{g} / \mathrm{g}$ in dogs treated with the highest to lowest doses, respectively. Similarly, tissue concentrations of drug in the spleen were $33.34 \mu \mathrm{g} / \mathrm{g}$, $19.86 \mu \mathrm{g} / \mathrm{g}$, and $11.63 \mu \mathrm{g} / \mathrm{g}$, respectively. Concentration of drug in the kidneys was similar in all three dogs. Evidence of mild gastritis was seen in the two dogs treated at higher dosages. In one dog, this gastritis was described as lymphocytic-plasmacytic.

\section{Pharmacokinetic data}

The values of pharmacokinetic parameters for intravenously administered CTI 52010 at six dose levels ranging from 60 to $240 \mathrm{mg} / \mathrm{m}^{2}$ are summarized in Table 4 . It was not possible to generate pharmacokinetic data at the $40 \mathrm{mg} / \mathrm{m}^{2}$ dosage because concentrations in all samples were below the limit of detection. The area under the curve ranged from $891 \mathrm{ng}$-hour $/ \mathrm{mL}$ to $1316 \mathrm{ng}$-hour $/ \mathrm{mL}$. The apparent elimination $\mathrm{t} 1 / 2_{0-24}$ ranged from 9.9 to 203.4 hours, with a median of 39.5 hours. The time

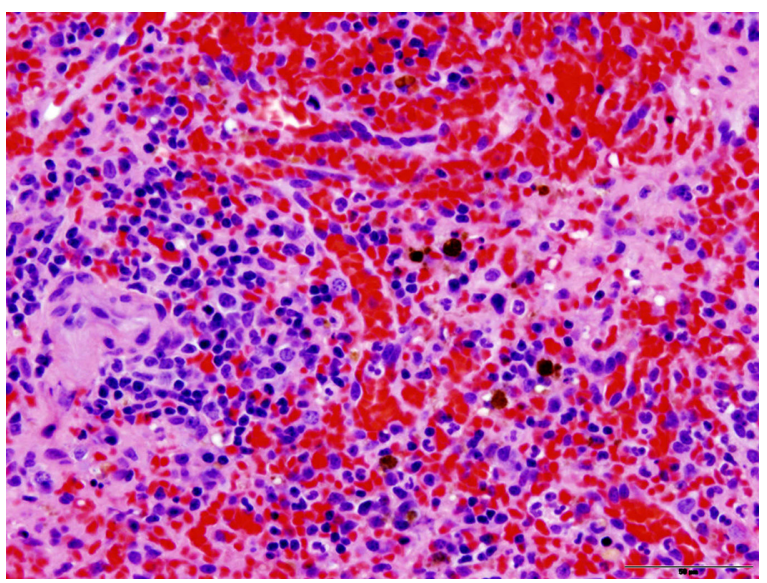

Figure 3 Histopathology of the spleen in a treated dog, showing no evidence of change compared with normal spleen. This picture also shows occasional macrophages that contain golden-brown pigment granules consistent with hemosiderin. 


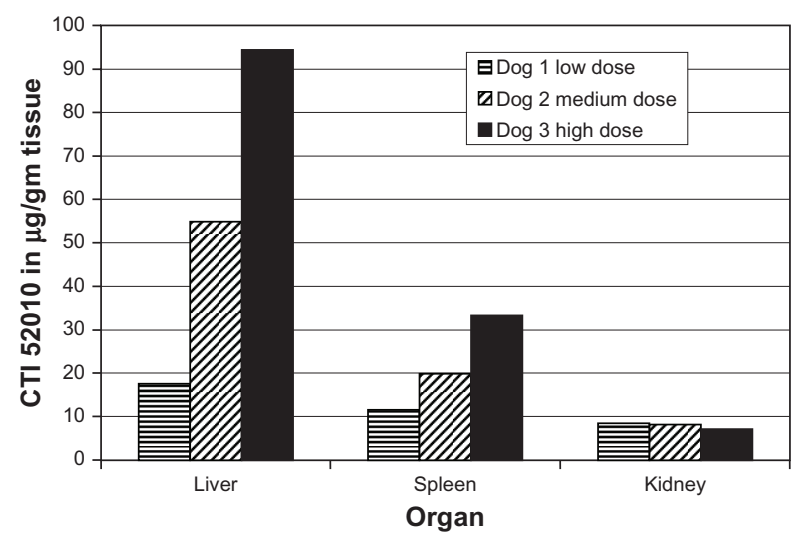

Figure 4 Tissue concentrations of CTI 52010. Accumulation of CTI 52010 was determined post mortem in the liver, kidney, and spleen of all three dogs using highpressure liquid chromatography following tissue homogenization and extraction.

to peak drug concentration was 0.5 hours, and the volume of distribution ranged from $1691 \mathrm{~L}$ to $2749 \mathrm{~L}$ (median $2251 \mathrm{~L}$ ). The maximum plasma concentration ranged from $319 \mathrm{ng} / \mathrm{mL}$ to $4531 \mathrm{ng} / \mathrm{mL}$ (median $2020 \mathrm{ng} / \mathrm{mL}$ ). The mean residence time was 8.8-258 (median 47.4) hours.

\section{Discussion}

The taxanes represent an important class of anticancer agents because of their broad spectrum of activity. Paclitaxel has limited solubility in water, and is most often formulated in a mixture with $50 \%$ ethanol and $50 \%$ polyethoxylated castor oil. Although effective at dissolving paclitaxel, these are thought to be the cause of acute hypersensitivity reactions observed during and following administration. Standard practice calls for premedication of patients with diphenhydramine, cimetidine or ranitidine, and dexamethasone to counteract the adverse effect of the solvents. Accordingly, several formulations of paclitaxel are being developed to eliminate the need for solvents. CTI 52010 is the simplest of these new formulations, consisting solely of drug and saline. The nanoparticle size and production method allow the nanoparticulate paclitaxel to exist stably without solvent, cosolvent, suspension-enhancing agents, or a stabilizing matrix.

Standard formulations of paclitaxel are not recommended for use in dogs due to their exquisite sensitivity to polyethoxylated castor oil; in 25 tumor-bearing dogs, 64\% had signs of an allergic reaction including hives, head shaking, skin flushing, and pruritus, despite heavy premedication using diphenhydramine, cimetidine, and dexamethasone. Other side effects noted with paclitaxel are similar to those noted in this study, including myelosuppression, vomiting, and diarrhea. ${ }^{4}$ These side effects are expected and for the most part easily treatable in canine cancer patients. Albumin-bound formulations of paclitaxel are also not advised for use in dogs, because an immediate or delayed hypersensitivity reaction occurs in healthy dogs when human albumin is administered. ${ }^{6}$

The aim of this study was to determine the maximum tolerated dose, toxicities, and pharmacokinetics of CTI 52010, a nanoparticulate paclitaxel without solubilizing agents, in normal dogs. The maximum tolerated dose was $120 \mathrm{mg} / \mathrm{m}^{2}$, and the dose-limiting toxicity was neutropenia. Gastrointestinal toxicity was mild and only seen in those dogs receiving high doses of drug. Because gastrointestinal toxicity is a major concern for pet owners pursuing chemotherapy for their dogs, this limited toxicity makes CTI 52010 an attractive chemotherapy agent. Biochemistry panel, urinalyses, coagulation parameters, prothrombin time, and partial thromboplastin time were evaluated in each dog prior to treatment (baseline) and one week after treatment. No clinically significant changes were seen in the coagulation panels in any dog, nor were significant changes noted in the biochemistry panel or urinalyses. On post mortem examination, no organ toxicity was noted. Hepatic detoxifying enzymes were not measured in this study. However, this could be considered in future studies as a possible explanation for pharmacokinetic variability. The intravenous administration of a nanoparticulate formulation of paclitaxel did not result in any evidence of a thrombotic event in any dog.

Table 4 Pharmacokinetic parameters for CTI 52010 determined after intravenous administration

\begin{tabular}{|c|c|c|c|c|c|c|c|}
\hline Parameter & Dosage & $60 \mathrm{mg} / \mathrm{m}^{2}$ & $80 \mathrm{mg} / \mathrm{m}^{2}$ & $90 \mathrm{mg} / \mathrm{m}^{2}$ & $120 \mathrm{mg} / \mathrm{m}^{2}$ & $160 \mathrm{mg} / \mathrm{m}^{2}$ & $240 \mathrm{mg} / \mathrm{m}^{2}$ \\
\hline AUC & & 891 & 577 & 509 & 285 & 1304 & 1316 \\
\hline \multicolumn{8}{|l|}{ (ng-hr/mL) } \\
\hline $\mathrm{tl} / 2_{0-24}$ & & 203.4 & 116.3 & 42.7 & 9.9 & 37.2 & 24.7 \\
\hline$V_{d}(L)$ & & 2288 & 2522 & 2749 & 2289 & 1691 & 2251 \\
\hline $\begin{array}{l}\mathrm{C}_{\max } \\
(\mathrm{ng} / \mathrm{mL})\end{array}$ & & 3545 & 327 & N/A & 319 & 4531 & 2020 \\
\hline $\begin{array}{l}\text { MRT } \\
\text { (area in hours) }\end{array}$ & & 258 & 161 & 57 & 8.8 & 37.8 & 29.8 \\
\hline
\end{tabular}

Abbreviations: AUC, area under the curve; MRT, mean residence time; $\mathrm{tl} / 2$, elimination half-life; $\mathrm{C}_{\max }$, peak plasma concentration. 
Furthermore, no evidence of hypersensitivity was noted in any dog, at any dosage, and no pretreatment was used in this study. Since CTI 52010 is a formulation of paclitaxel consisting solely of paclitaxel and saline, it does not cause hypersensitivity, and a new class of chemotherapeutics can be added to the current repertoire of drugs commonly used to treat canine cancer.

The apparent $t 1 / 2_{0-24}$ ranged from 9.9 hours to 203.4 hours. This long and variable half-life is possibly due to drug accumulation in the liver and spleen. Previous studies using the standard formulation of paclitaxel solubilized with polyethoxylated castor oil revealed a terminal t1/2 of 1.9 hours. ${ }^{15}$ The prolonged $\mathrm{t} 1 / 2$ in CTI 52010 can be exploited for therapeutic gain in tumors of the liver and spleen, providing a potential therapeutic advantage over standard paclitaxel formulations. We chose a 28-day washout period between treatments based on the metabolism and clearance of other chemotherapeutic agents, and without prior knowledge of the extended half-life. However, despite the possibility of drug accumulation contributing to toxicity, this study design did allow us to achieve our goals. It is possible that our starting dosage for a Phase II trial in tumor-bearing dogs will be low if drug accumulation contributed to toxicity, because adverse events would have been detected at lower dosages. Therefore, a rapid dose escalation scheme is appropriate for a Phase II trial in tumor-bearing dogs.

There was minimal accumulation of CTI 52010 in the kidneys, which is in contrast with other nanoparticulate formulations of paclitaxel studies in mice. However, many nanoparticulate formulations use a polymeric coating such as gelatin. ${ }^{15}$ CTI 52010 is produced using precipitation with compressed antisolvents, and polymeric coatings are not needed. Due to the production methods used, CTI 52010 contains only paclitaxel in nanoparticulate form, and avoids the toxicities associated with gelatin or other matrices used in other nanoparticle production methods.

Standard formulations of paclitaxel result in low levels of uptake in the liver and spleen, while liposomal paclitaxel accumulates in the lungs. ${ }^{16}$ In contrast, accumulation of CTI 52010 was noted in the spleen and liver of all dogs in this study, with concentrations highest in the dog administered the highest cumulative dosage. Drug accumulation in these two organs is likely due to nanoparticle uptake by macrophages in the reticuloendothelial system, a phenomenon that may be exploited for therapeutic gain against certain tumor types. Histiocytic sarcomas, for example, are a common cancer type originating from macrophages and dendritic cells in both the liver and spleen. There are currently no effective chemotherapeutic agents for liver cancer or histiocytic cancers, and the accumulation of CTI 52010 in the liver and spleen makes it an attractive agent for the treatment of these cancer types. Additionally, taxanes have shown preliminary efficacy in breast and bone cancer in dogs. Two dogs with metastatic mammary carcinoma and two dogs with metastatic osteosarcoma treated with standard paclitaxel experienced a partial remission. All of these dogs were resistant to other chemotherapeutics. ${ }^{4}$ These two types of cancer are common canine malignancies, yet no recent research has provided a change in the current standard of care. There are many cancers for which CTI 52010 has the potential to be used to treat tumor-bearing dogs effectively, thus improving their quality of life. With the maximum tolerated dose and dose-limiting toxicity determined in this study, a Phase II trial can be initiated for dogs with spontaneously occurring cancer to obtain more pharmacokinetic and antitumor efficacy data.

Dogs also serve as a model for people and can guide the development of novel chemotherapy and biological or targeted treatments for cancer in both species. ${ }^{11-13}$ Currently, a Phase I study of nanoparticulate paclitaxel administered via the intraperitoneal route to human cancer patients is underway. The pharmacokinetic and toxicity data provided by our study can improve the efficiency of the drug development pathway, offering a new route of administration of nanoparticulate paclitaxel, thus further benefiting human cancer patients. Furthermore, using the novel system precipitation with compressed antisolvent to produce CTI 52010, stable suspensions of paclitaxel nanoparticles in physiologic saline are formed and easily injected as a suspension. This preparation is ideal, because it is devoid of polyethoxylated castor oil and its undesirable side effects, and allows controlled particle size distribution and consistent product quality. ${ }^{7}$

In conclusion, the study reported here demonstrates the maximum tolerated dose, dose-limiting toxicity, and pharmacokinetics of CTI 52010 in normal dogs. The results of this study indicate that a Phase II efficacy trial in tumor bearing dogs is feasible, and provide a starting point for dosing in future trials.

\section{Acknowledgment}

This project was supported by a Kansas City Area Life Sciences Institute grant.

\section{Disclosure}

CD is a Senior Research Fellow and JH is Director of Laboratory Operations for CritiTech Inc, manufacturer of CTI 52010. This work was presented in poster form at the 


\section{0th Annual Veterinary Cancer Society Conference, San Diego, CA, October 2010.}

\section{References}

1. Schiff PB, Fant J, Horwitz SB. Promotion of microtubule assembly in vitro by taxol. Nature. 1979;22:665-667.

2. Wani MC, Taylor HL, Wall ME, et al. Plant antitumor agents. VI. The isolation and structure of Taxol, a novel antileukemic and antitumor agent from Taxus brevifolia. J Am Chem Soc. 1971;93:2325-2327.

3. Singla AK, Garg A, Aggarwal D. Paclitaxel and its formulations. Int $J$ Pharm. 2002;235:179-192.

4. Poirier VJ, Hershey AE, Burgess KE, et al. Efficacy and toxicity of paclitaxel (Taxol) for the treatment of canine malignant tumors. $J$ Vet Intern Med. 2004;18:219-222.

5. Miele E, Spinelli GP, Miele E, et al. Albumin-bound formulation of paclitaxel (Abraxane $\left.{ }^{\circledR} \mathrm{ABI}-007\right)$ in the treatment of breast cancer. Int $J$ Nanomedicine. 2009;4:99-105.

6. Francis AH, Martin LG, Haldorson GJ, et al. Adverse reactions suggestive of type III hypersensitivity in six healthy dogs given human albumin. $J \mathrm{Am}$ Vet Med Assoc. 2007;230:873-879.

7. Roby KF, Niu F, Rajewski RA, et al. Syngeneic mouse model of epithelial ovarian cancer: effects of nanoparticulate paclitaxel, Nanotax ${ }^{\circledR}$. Adv Exp Med Biol. 2008;622:169-181.

8. Bulitta JB, Zhao P, Arnold RD, et al. Mechanistic population pharmacokinetics of total and unbound paclitaxel for a new nanodroplet formulation versus Taxol in cancer patients. Cancer Chemother Pharmacol. 2009;63:1049-1063.
9. Niu F, Roby KF, Rajewski RA, et al. Paclitaxel nanoparticles: production using compressed $\mathrm{CO} 2$ as antisolvent, characterization and animal modeling studies. Polymeric Drug Delivery Volume II - Polymeric matrices and drug particle engineering. Svenson S. J Am Chem Soc. 2006;924:262-277.

10. Tanaka T, Decuzzi P, Cristofanilli M, et al. Nanotechnology for breast cancer therapy. Biomed Microdevices. 2009;11:49-63.

11. Khanna C, London C, Vail D, et al. Guiding the optimal translation of new cancer treatments from canine to human cancer patients. Clin Cancer Res. 2009;15:5671-5677.

12. Paoloni M, Khanna C. Translation of new cancer treatments from pet dogs to humans. Nat Rev Cancer. 2008;8:147-156.

13. Vail DM, MacEwen EG. Spontaneously occurring tumors of companion animals as models for human cancer. Cancer Invest. 2000;18: 781-792.

14. Veterinary Cooperative Oncology Group. Veterinary Co-operative oncology group - common criteria for adverse events (VCOG-CTCAE) following chemotherapy or biological antineoplastic therapy in dogs and cats v1.0. Vet Comp Oncol. 2004;2:194-213.

15. Yeh TK, Lu Z, Wientjes MG, Au JL-S. Formulating paclitaxel in nanoparticles alters its disposition. Pharm Res. 2005;22:867-874.

16. Zhao L, Ye Y, Li J, Wei Y. Preparation and the in-vivo evaluation of paclitaxel liposomes for lung targeting delivery in dogs. $J$ Pharm Pharmacol. 2011;63:80-86.
International Journal of Nanomedicine

\section{Publish your work in this journal}

The International Journal of Nanomedicine is an international, peerreviewed journal focusing on the application of nanotechnology in diagnostics, therapeutics, and drug delivery systems throughout the biomedical field. This journal is indexed on PubMed Central, MedLine, CAS, SciSearch ${ }^{\circledR}$, Current Contents ${ }^{\circledR} /$ Clinical Medicine,

\section{Dovepress}

Journal Citation Reports/Science Edition, EMBase, Scopus and the Elsevier Bibliographic databases. The manuscript management system is completely online and includes a very quick and fair peer-review system, which is all easy to use. Visit http://www.dovepress.com/ testimonials.php to read real quotes from published authors. 